\title{
Study on the Dynamic Impulse of Stock Market Order Flow on Return
}

\author{
Chenggang $\mathrm{Li}^{1,2, \mathrm{a}^{*}}$, Xiaoliang $\mathrm{Liu}^{1, \mathrm{~b}}$, Cong Luo ${ }^{3, \mathrm{c}}$, Yandan Xue ${ }^{1, \mathrm{~d}}$, Mingguo \\ Zhang $^{1, e}$, Lingyun Luo ${ }^{1, f}$ \\ ${ }^{1}$ Faculty of Finance, Guizhou University of Finance and Economics, Guiyang, 550025, China; \\ ${ }^{2}$ Faculty of Science, National University of Singapore, 117546, Singapore; \\ ${ }^{3}$ Experimental Teaching Department, Guizhou University of Finance and Economics, Guiyang, \\ 550004
}
a895977948@qq.com, b330492099@qq.com, 'locong@126.com; d1532895790@qq.com, flly089@163.com

*The corresponding author

\section{Keywords: Stock market; Order flow; Return; Dynamic impulse}

\begin{abstract}
Studying on the dynamic impulse of stock market order flow on the return is beneficial for the investors to make accurate investment decisions. This paper use Cointegration test and Granger causality test, constructs the VAR model and select the data from October 1, 2010 to December 31, 2014, to empirically analyze the dynamic relationship between stock market order flow and return. The empirical results show that the effect of lagged first order flow on the stock return is 1.1710, and the effect of the lagged second order flow is 0.5776. The impact of the lagged first order and second orders is significant under the $1 \%$ level. The impact on the return is gradually reduced to the minimum in the third phase, and then gradually becomes larger, in the sixth phase gradually achieve smooth, and gradually disappear.
\end{abstract}

\section{Introduction}

With the development of the micro structure theory of financial market, the influence of the micro structure variables (such as the order flow and liquidity) on the return of the financial market is more and more concerned by the academics. Among them, the most concern is the impact of stock order flow on stock returns. Order flow reflects the flow of funds, and reflects the investors' investment preferences and investment trends. In the stock market, the change of stock order flow will impact on the stock return. Due to the change of order flow will affect the investor's investment return and the investors' investment decisions, the research on the impact of order flow on stock return can guide investors to make the right investment decisions according to the changes of order flow.

Many scholars have conducted deep researches on the relationship between stock market order flow and return. Chordia and Subramanian (2004) [2] empirically studies the relation between order imbalances and daily returns of individual stocks. The empirical results show that, price pressures caused by auto correlated imbalances cause a positive relation between lagged imbalances and returns and imbalance-based trading strategies return statistically significant returns. Harford and Kaul (2005) [2] study the US stock market, and find that the stock order flow can explain the stock return. Bailey etc. (2009) [3] empirically test the relationship between the Shanghai stock market return and order imbalance. The results show that order imbalance of the institutional investors (property right) has greater influence on return, and the generality of individual investors order imbalance is stronger. Mu et al (2010)[4] study the dynamics of order flows around large intraday price changes using ultra-high-frequency data from the Shenzhen Stock Exchange. They find a significant reversal of price for both intraday price decreases and increases with a permanent price impact. Li et al (2011) [5] use event study analysis to study the stock characteristics which are recommended by the securities analysts. They find that the symbols of abnormal return and abnormal order flow of stocks that securities analysts recommend are the same, and are significant under $1 \%$ level. Then the stock selection method based on the order flow is proposed. Luo et al 
(2011) [6] analyze the interaction relationship of order flow, liquidity and return between different market value stocks, and find that small-cap stocks rise, then order flow large-cap stocks returns drop significantly in the future. Li et al (2015) [7] think a stock order flow impacts the stock returns, and build dynamic investment strategy based on the order flow respectively. Hanke and Weigerding (2015) [8] study how the order flow imbalance effects on the German stock market. They provide evidence for size and liquidity effects and analyze changes in imbalance effects during the financial crisis.

From the results of the above researches, we can see that, most of the research results show that the order flow will affect the stock return, and will impulse on the return. However, these studies have not yet discussed the dynamic impact of stock order flow on the stock return, and the dynamic impact of stock order flow on return has not yet been studied. In this paper, we construct a vector autoregressive model (VAR), and empirically analyze the dynamic impact process of stock order flow on return.

\section{Variable Selection and Model Construction}

Variable Selection. Return $(r)$. Stock market return is measured by the return of Shanghai Composite Index. We use the following formula to calculate the return of Shanghai Composite Index:

$$
r_{t}=\log P_{t}-10 q_{1}
$$

Wherein, $r_{t}$ is the ${ }^{t}$ th day's return of Shanghai Composite Index; ${ }^{P_{t}}$ is the ${ }^{t}$ th day's closing price of Shanghai Composite Index.

Order flow ( ${ }^{o f}$ ). First of all, according to Lee and Ready (1991) [9], the method of judging the direction of each transaction is initiated by the buyer or the seller. We will each deal clinch a deal valence comparing with trade quotes halfway point, if the price is higher than the quote midpoint, we think the deal initiated by the buyer; If the price is lower than the price point, we believe that the deal was sponsored by the seller.

Because calculating the difference of transaction initiated by the buyer and the seller, so this article only to identify with the different deal of price quote midpoint and transaction price. Using the method of Underwood (2009) [10], this paper defines every transaction initiated by the buyer and the seller of balance of transaction amount as the flow of the order on the day.

Model Construction. In order to reflect the impulse of stock market order flow on the return, this paper constructs a two variable vector autoregressive model of order flow and return. The two variable VAR model constructed in this paper is as follows:

$$
\left[\begin{array}{c}
r \\
o f
\end{array}\right]=\left[\begin{array}{l}
c_{1} \\
c_{2}
\end{array}\right]+\left[\begin{array}{ll}
\pi_{11} & \pi_{12} \\
\pi_{21} & \pi_{22}
\end{array}\right]\left[\begin{array}{c}
r_{t-1} \\
o f_{t-1}
\end{array}\right]+\left[\begin{array}{ll}
\theta_{11} & \theta_{12} \\
\theta_{21} & \theta_{22}
\end{array}\right]\left[\begin{array}{c}
r_{t-2} \\
o f_{t-2}
\end{array}\right]+\cdots+\left[\begin{array}{ll}
\phi_{11} & \phi_{12} \\
\phi_{21} & \phi_{22}
\end{array}\right]\left[\begin{array}{c}
r_{t-p} \\
o f_{t-p}
\end{array}\right]+\left[\begin{array}{l}
\mu_{1} \\
\mu_{2}
\end{array}\right]
$$

Wherein, $r$ is the stock market return. of is the stock market order flow. $\pi, \theta$ and $\phi$ are the parameters to be estimated. $\mu$ is the error term.

\section{Empirical Analysis}

Data Sources. This paper selects the closing price data of the Shanghai Composite Index and order flow data from January 1, 2010 to December 31, 2014. During this time interval, there are rise period and decline period. There is also a period of consolidation. So this period can better reflect the different market status of China's stock market. The data of this paper come from the Guo Tai An CSMAR China stock exchange database and the high frequency database.

Empirical Results Analysis. Unit root test. Due to the non-stationary time series modeling may cause a "pseudo regression" phenomenon, we need to do a unit root test for the variable before modeling. In this way, we can determine whether a variable is a stationary time series. In this paper, 
the ADF test and PP test are used to carry out unit root test. Test results are shown in Table 1. From the test results, it can be seen that stock order flow and return are stable time series.

Table 1 Unit root test results

\begin{tabular}{|c|c|c|c|c|}
\hline \multirow{2}{*}{ Sequence } & \multicolumn{2}{|c|}{ ADF test } & \multicolumn{2}{c|}{ PP test } \\
\cline { 2 - 5 } & T statistic & Prob & T statistic & Prob \\
\hline$r$ & -4.9509 & 0.0028 & -4.9263 & 0.0023 \\
\hline of & -14.0862 & 0.0013 & -14.0791 & 0.0010 \\
\hline
\end{tabular}

Co-Integration Test. There are two main methods of co-integration test. They are EG test and JJ test. Because the $\mathrm{JJ}$ test is based on the maximum likelihood estimation method which bases on the vector auto-regressive framework, the JJ test method is a method to test the multivariable co-integration relationship. It allows immediate interaction between variables. Therefore, this article uses the JJ test method to carry on the co-integration test. Test results are shown in Table 2. JJ test results show that the co-integration relationship between stock order flow and the return, that is, there is a long-term stable equilibrium relationship.

Table 2 JJ co-integration test results

\begin{tabular}{|c|c|c|c|c|}
\hline \multicolumn{5}{|c|}{ Characteristic root locus test } \\
\hline Original hypothesis & $\begin{array}{c}\text { characteristic } \\
\text { value }\end{array}$ & $\begin{array}{c}\text { Maximal Eigenvalue } \\
\text { Statistic }\end{array}$ & $5 \%$ critical value & $\begin{array}{c}\mathrm{P} \\
\text { value*** }\end{array}$ \\
\hline None $*$ & 0.4620 & 18.6236 & 14.3622 & 0.037 \\
\hline At most $1 *$ & 0.2529 & 5.6247 & 4.6253 & 0.0423 \\
\hline At most 2 & 0.0162 & 0.1264 & 2.9518 & 0.8261 \\
\hline \multicolumn{5}{|c|}{ Max-eigenvalue test indicates 1 cointegrating eqn(s) at the 0.05 level } \\
\hline \multicolumn{5}{|c|}{$*$ denotes rejection of the hypothesis at the 0.05 level } \\
\hline \multicolumn{5}{|c|}{ **MacKinnon-Haug-Michelis (1999) p-values } \\
\hline \multicolumn{5}{|c|}{ the maximum eigenvalue test } \\
\hline Original hypothesi & $\begin{array}{c}\text { characteristic } \\
\text { value }\end{array}$ & $\begin{array}{c}\text { Maximal Eigenvalue } \\
\text { Statistic }\end{array}$ & $5 \%$ critical value & $\begin{array}{c}\text { The } \\
\text { value of } \\
\mathrm{P} * *\end{array}$ \\
\hline None * & 0.6952 & 17.6215 & 20.3992 & 0.0043 \\
\hline At most $1 *$ & 0.3193 & 13.3619 & 12.6217 & 0.0160 \\
\hline At most 2 & 0.2284 & 1.3260 & 1.6061 & 0.3050 \\
\hline \multicolumn{5}{|c|}{ Max-eigenvalue test indicates no co-integration at the 0.05 level } \\
\hline \multicolumn{5}{|c|}{$*$ denotes rejection of the hypothesis at the 0.05 level } \\
\hline \multicolumn{5}{|c|}{ **MacKinnon-Haug-Michelis (1999) p-values } \\
\hline
\end{tabular}

Granger causality test. Co-integration test shows that there is a long-term stable relationship between stock order flow and return. However, whether the order flow has impacts on the return or the return has impacts on the order flow, or they have impacts on each other, need further to be tested. This article uses the Granger causality test method to carry on the inspection .The inspection results are as shown in Table 3. From the test results in Table 3, we can see that there is a two-way Granger causality between stock market order flow and return. Therefore, the stock market order flow and return interact. 
Table 3 Granger causality test results

\begin{tabular}{|l|c|c|c|}
\hline Null Hypothesis: & Obs & F-Statistic & Prob. \\
\hline R does not Granger Cause OF & \multirow{2}{*}{1212} & 9.6232 & 0.0000 \\
\cline { 1 - 1 } \cline { 4 - 4 } OF does not Granger Cause R & & 9.4326 & 0.0000 \\
\hline
\end{tabular}

Estimation results of VAR model. In this paper, the model (2) is used to analyze the impact of stock market order flow on return. Before the estimation of model (2), it is necessary to determine the lag order. When choosing the lag order, we should consider the dynamic characteristics of the constructed model, and the sufficient degree of freedom. The test results of the optimal lag order of the 0-5 lag order VAR model are shown in Table 4.

Table 4 Determination of the lag order

\begin{tabular}{|c|c|c|c|c|c|c|}
\hline Lag order & $\log \mathrm{L}$ & LR & FPE & AIC & SC & HQ \\
\hline 0 & 38.9931 & NA & 0.1135 & 2.3504 & 1.6933 & 7.8939 \\
\hline 1 & 38.9122 & 20.9051 & 0.1127 & 2.3483 & 1.6902 & 7.8830 \\
\hline 2 & 38.9098 & 20.9042 & 0.1122 & 2.3406 & 1.6872 & 7.8813 \\
\hline 3 & 38.9252 & 20.9125 & 0.1129 & 2.3492 & 1.6836 & 7.8811 \\
\hline 4 & 38.9403 & 20.9137 & 0.1134 & 2.3506 & 1.6884 & 7.8825 \\
\hline 5 & 39.9739 & 20.9185 & 0.1139 & 2.3517 & 1.6947 & 7.8836 \\
\hline
\end{tabular}

According to the results of Table 4, combined with the statistical values of the statistics, the optimal lag order of the VAR model is 2 . Therefore, the VAR model used to examine the impact of the stock market order flow on the return is as the following:

$$
\left[\begin{array}{c}
r \\
o f
\end{array}\right]=\left[\begin{array}{l}
c_{1} \\
c_{2}
\end{array}\right]+\left[\begin{array}{ll}
\pi_{11} & \pi_{12} \\
\pi_{21} & \pi_{22}
\end{array}\right]\left[\begin{array}{c}
r_{t-1} \\
o f_{t-1}
\end{array}\right]+\left[\begin{array}{ll}
\theta_{11} & \theta_{12} \\
\theta_{21} & \theta_{22}
\end{array}\right]\left[\begin{array}{c}
r_{t-2} \\
o f_{t-2}
\end{array}\right]+\left[\begin{array}{c}
\mu_{1} \\
\mu_{2}
\end{array}\right]
$$

Using the Eviews6.0 to estimate model (3), from the estimation results, the fitting effect of the model is good. The values of AIC and SCI are small, and the selection of the lag order of the model is reasonable. Analyzing the estimation results, it can be found: the impact of the first order lag of the order flow on the return is 1.1710 , and the impact of the second order lag of the order flow on the return is 0.5776 . All the impact is significant under the $1 \%$ level. Therefore, the order flow has a significant effect on the return, and the impact is positive (For space consideration, the VAR(2) model estimation results are not list here).

In order to intuitively describe the dynamic impact process of stock order flow, this paper constructs the impulse response function based on the results of VAR (2) model. The impulse response function diagram is shown in Figure 1. Figure 1 depicts the dynamic impulse of stock market order flow on return. Figure 2 shows that the impact of order flow on the return gradually reduced, reaching a minimum in the third phase, and then gradually become larger, in the sixth period gradually reaching a stable, and gradually disappear. According to the above analysis, the order flow has a significant positive effect on the return. The impact of order flow on return is constantly changing. 


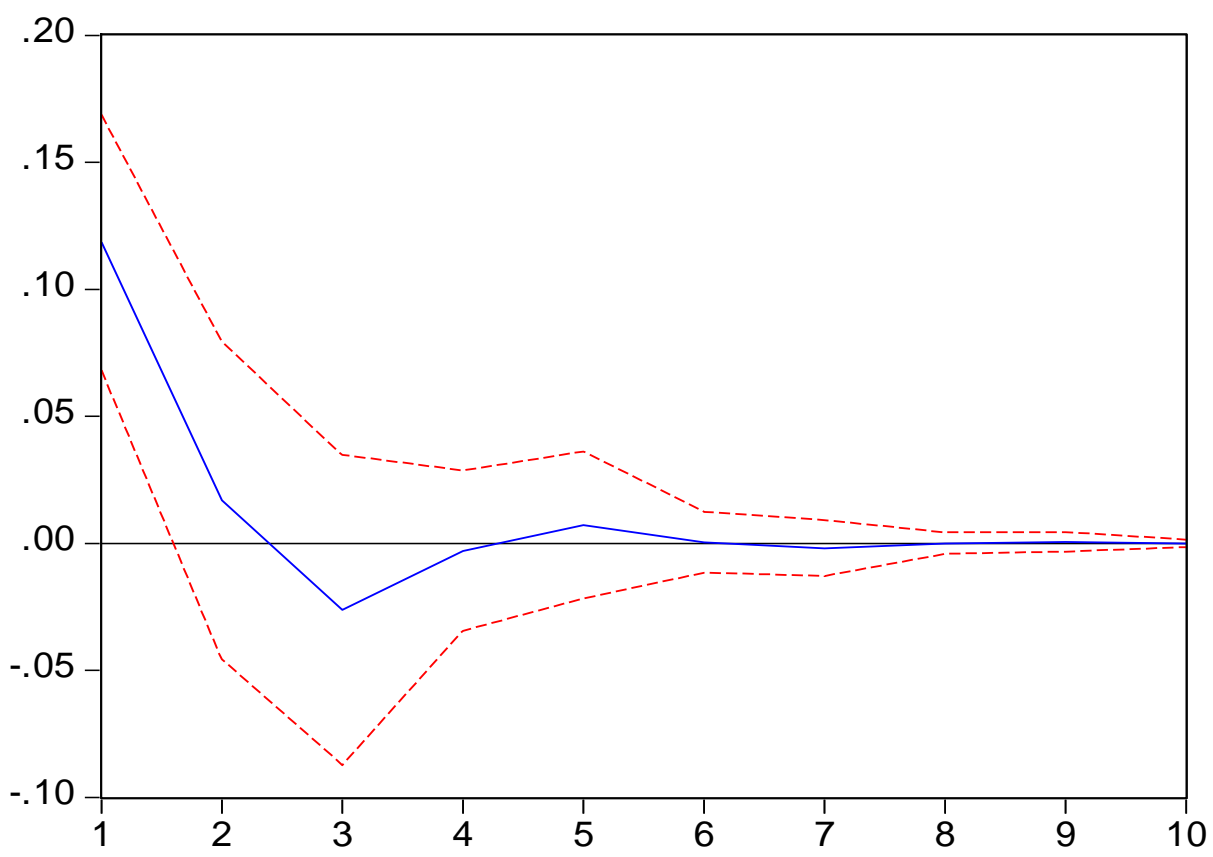

Figure 1 The response function of the rate of return to the order flow

\section{Conclusions}

This paper uses co-integration test and Granger causality test, constructs VAR model, and empirically analyzes the dynamic impact effect of stock market order flow on return. In this paper, the VAR(2) model of order flow and return is constructed, and the data from January 1, 2010 to December 31, 2014 are selected to do empirical analysis. The empirical results show that, there are Cointegration and two-way Granger causality between stock order flow and return. The effect of lagged first order flow on the stock return is 1.1710, and the effect of the lagged second order flow is 0.5776 . The impact of the lagged first order and second orders is significant under the $1 \%$ level. The impact on the return is gradually reduced to the minimum in the third phase, and then gradually becomes larger, in the sixth phase gradually achieve smooth, and gradually disappear.

\section{References}

[1] T. Chordiaa, A. Subrahmanyam, Order imbalance and individual stock returns: Theory and evidence, Journal of Financial Economics. 72 (2004) 485-518.

[2] J. Harford, A. Kaul, Correlated order flow: Pervasiveness, sources, and pricing effects, Journal of Financial and Quantitative Analysis. 40 (2005) 29-55.

[3] W. Bailey, J. Cai, L. C. Yan, et al, Stock returns, order imbalances, and commonality: Evidence on individual institutional, and proprietary investors in China, Journal of Banking \& Finance. 33 (2009) 9-19.

[4] G. H. Mu, W. X. Zhou, W. Chen, et al, Order flow dynamics around extreme price changes on an emerging stock market, New Journal of Physics. 12 (2010) 1-21.

[5] C.G. Li, Y.X. Tian, C. Luo, et al, Comparative study on order flow and analyst stock selection return based on NBC, Systems Engineering. 29 (2011): 7-14.

[6] M. Luo, Y.X. Tian, F. Jin, et al, Order flow, liquidity and flight on the stock market, Management Review. 23 (2011) 131-137. 
[7] C.G. Li, C. Luo, J.B. Hu, Dynamic investment strategy based on order flow and its empirical study, Chinese Journal of Management Science. 30 (2015) 148-156.

[8] M. Hanke, M. Weigerding, Order flow imbalance effects on the German stock market, Business Research. 8 (2015) 213-238.

[9] C. Lee, M. Ready, Inferring trade direction from intraday data, Journal of Finance. 46 (1991) 733-746.

[10] S. Underwood, The cross-market information content of stock and bond order flow, Journal of Financial Markets, 12 (2013) 268-289. 